\title{
EDITORIAL
}

\section{Prevenir el cáncer bucal es salvar una vida}

\section{Jose Ángel García Artiga. M.S.D. ${ }^{1}$}

Cuando hablamos de cáncer a cualquier persona en la clínica manifiesta temor a la muerte, cuando en realidad es una enfermedad que al descubrirla en su etapa inicial es curable. Resulta sorprendente ver que hay una buena cantidad de población que se extraña al conocer que el cáncer puede aparecer en la boca. Existe un principio que debería ser conocido y ser practicado por todos: "Toda lesión ulcerada, roja, blanca o nodular que se encuentre en la cavidad bucal, que con o sin tratamiento no desaparezca después de 15 días, debe ser considerada cáncer mientras no se compruebe lo contrario", podemos agregar a lo anterior que si la lesión sangra con o sin estímulo, crece rápidamente o cambia de color, la sospecha debe ser mayor. Esto parece ser muy radical; pero si estamos hablando de curar el cáncer en sus etapas iniciales o tempranas esto debe ser cumplido.

Punto básico para el padecimiento de cáncer es la genética de la persona, a medida que el tiempo transcurre, las investigaciones médicas sobre esta enfermedad están demostrando la tendencia familiar y de errores genéticos a padecerlo. Ejemplo de ello es el cáncer de mama en las mujeres, en donde al efectuar un árbol genealógico encontramos como abuelas, madres, hijas y tías o hermanos de una misma familia que han padecido la enfermedad, no solo cáncer de mama; sino que la predisposición familiar está dada para cáncer en cualquier parte del organismo.

Un factor de riesgo para el cáncer de la boca es cualquier acción que hace más propensa a la persona a padecer de cáncer, y aunque varios de ellos pueden estar presentes en una persona, no necesariamente desarrollará cáncer; pero, además, existen personas que desarrollan cáncer y no tienen asociado ningún factor de riesgo.

En odontología se consideran factores de riesgo una higiene deficiente (falta de buen cepillado), prácticas sexuales bucales, estrés, dientes fracturados por traumatismos o caries, restauraciones mal adaptadas, tabaquismo, alcoholismo, exposición UV solar (piel de labios), cualquier hábito que irrite crónicamente la mucosa bucal; algunos autores creen que la ingestión de alimentos muy calientes y muy condimentados pueden ser considerados factores predisponentes.

La prevención es el factor determinante para protegerse de los efectos secundarios de los tratamientos mutilantes del cáncer bucal, especialmente, los quirúrgicos, pues, tanto 
funcional como estéticos, destruyen la moral y el cuerpo del paciente, no es lo mismo perder incluso un miembro inferior completo que la lengua, mandíbula o maxilar superior en donde incluso la órbita de un ojo tiene que ser extirpada.

Tanto los odontólogos como las instituciones gubernamentales de salud somos responsables que la población en mayor número esté padeciendo la enfermedad. Debería de existir los fondos necesarios para que personas preparadas para el caso fueran constantemente a poblaciones del país y junto con las alcaldías, en empresas, escuelas y grupos sociales ya formados, informando ampliamente a la población de como evitar al máximo dicha enfermedad. A la larga es más económico que los tratamientos y productivamente menos dañino para las empresas, pues, personal altamente preparado no se pierde.

Debe educarse a la población a que consulte a su odontólogo, al menos una vez al año, para revisar toda la boca y descartar en fase inicial lesiones que puedan ser cáncer, NO solamente para restaurar lesiones en dientes con caries o alguna rehabilitación protésica por estética.

${ }^{1}$ Doctor en Cirugía Dental. Área de Medicina y Cirugía Bucal. Facultad de Odontología de la Universidad Evangélica de El Salvador. jose.garcia@uees.edu.sv 